\title{
MAPEAMENTO DOS IMPACTOS AMBIENTAIS DO SETOR DE MINERAÇÃO NO ESTADO DE MINAS GERAIS
}

Nome do Autor (a) Principal

Jéssica dos Santos Leite Gonella

Nome (s) do Coautor (a) (s)

Alana Maziero Reinas e Juliana Abril Parra

Nome (s) do Orientador (a) (s)

Prof ${ }^{a}$. Drª . Angélica Góes Morales

Instituição ou Empresa

Universidade Estadual Paulista Júlio de Mesquita Filho (UNESP)

E-mail de contato: Jessica gonella@hotmail.com

Palavras-chave

Impactos ambientais. Mineração. Minas Gerais.

\section{INTRODUÇÃO}

O presente trabalho busca diagnosticar quais são as principais características da mineração, bem como os impactos que são causados ao meio ambiente, principalmente no estado de Minas Gerais. A palavra mineração é derivada do latim e seu significado é relativo a minas e minerais. Pode-se definir a atividade, como a extração de minérios presentes no solo ou existentes em rochas, sem que $o$ ato destrua as características primárias do recurso (AMARAL; LIMA FILHO, 2015).

A Organização das Nações Unidas (ONU) adota uma classificação com padrões internacionais que definem três tipos de minerais, sendo eles: gasosos, como o gás natural; líquido, como o petróleo em seu estado bruto; e sólido, como o 
ouro e o cobre (AMARAL; LIMA FILHO, 2015). Ressalta-se ainda que o subsolo brasileiro possui reservas minerais importantes e com grande diversidade, considerando que 0 país produz aproximadamente setenta substâncias diferentes, sendo que quatro delas pertencem ao grupo dos minerais energéticos, quarenta e cinco dos não metálicos e vinte e uma dos metálicos. No ano de 2000, no que diz respeito à participação no mercado mundial, o Brasil seguia como o segundo maior produtor de minérios de ferro, o que considera um dado importante para evidenciar que a mineração é uma prática de alta relevância em diversos aspectos no país (FARIAS, 2012).

No ano de 2014, o setor de minérios representava cerca de 5\% do Produto Interno Bruto (PIB) em nível global, e em 2013 as exportações brasileiras foram de aproximadamente $23,5 \%$, o que gerou US\$ 85 bilhões em receita para o PIB nacional. Dessa forma, corrobora-se a importância do setor na economia do país e do mundo, visto que a sua prática contribui para geração de emprego e aumento de renda, aquecendo o mercado em âmbito geral (BRASIL, 2014).

Os minérios são capazes de gerar uma infinidade de produtos derivados para o consumo humano, e como em geral sua retirada do meio natural acontece em locais afastados dos centros urbanos, nem todas as pessoas conhecem os impactos que tal prática é capaz de gerar. É importante ressaltar, que sua extração pode trazer consequências em curto, médio ou longo prazo, sendo que a última se destaca tanto em gravidade quanto em dificuldade de reversão dos seus possíveis efeitos negativos (PENNA, 2009).

Dentro do território nacional, o Estado que ganha destaque no setor de mineração é Minas Gerais, sendo responsável por aproximadamente 29\% de toda a produção de minérios de forma geral e $53 \%$ da produção de minerais metálicos. Salienta-se ainda que das cem maiores minas do Brasil, quarenta delas estão localizadas neste Estado, e entre os dez principais municípios mineradores do país, sete deles se encontram em Minas Gerais, sendo Itabira a cidade com maior produção (IBRAM, 2015).

No que diz respeito à exportação no Estado, tem-se que $52,8 \%$ do total exportado são representados por minerais. Evidencia-se que em 2013 a balança comercial em Minas Gerais resultou um saldo de US $\$ 18.117,8$ bilhões, e em 2.014, 
US\$14.295,7 bilhões. Com base nesses dados, observa-se a real importância do setor de mineração para o território mineiro (IBRAM, 2015).

Entre todos os estados brasileiros, Minas Gerais possui a terceira maior produção de níquel, a segunda maior produção de bauxita e a maior reserva de manganês. Como principais minérios produzidos no Estado, destacam-se: ferro, ouro, prata, cobalto, enxofre, barita, nióbio, dolomito, entre outros (IBRAM, 2015).

Diante do contexto apresentado, conserva-se o pensamento da importância do setor dentro do cenário nacional e internacional, bem como a relevância de entender os principais impactos que o mesmo gera ao meio ambiente, de modo que a exploração ocorra de forma mais consciente e com menor intensidade, acentuando-se que os minerais são recursos finitos, ao mesmo tempo em que necessários para o aquecimento econômico em esfera global.

\section{OBJETIVO}

Deste modo, esse estudo teve como objetivo mapear quais são os aspectos e impactos ambientais positivos e negativos oriundos do setor de mineração no Estado de Minas Gerais, bem como compreender as principais características da prática desta atividade.

\section{METODOLOGIA}

Para a realização desse diagnóstico dos impactos, utilizou-se de material de cunho bibliográfico e teórico. Portanto, o presente estudo foi pautado em livros e artigos científicos relacionados ao tema disponíveis em bases científicas, proporcionando conhecimentos para o ensaio teórico, baseado na abordagem qualitativa.

A pesquisa bibliográfica se faz importante à medida que aproxima o pesquisador dos principais estudos já efetivados, provocando o enriquecimento teórico e a busca pelos resultados, de modo a atingir o objetivo proposto. 


\section{RESULTADOS}

Os impactos causados pela mineração dão-se desde o século XVII, no qual a exploração estava se iniciando de maneira compulsória e errônea acarretando destruição do meio ambiente. Tal fato atrelado à disparidade da população que migrou para regiões próximas das minas, locais sem saneamento básico, gerou discrepância social neste período com o surgimento de muitas doenças originárias desses fatores (ENRÍQUEZ, 2009).

O Estado de Minas Gerais sofre com as consequências da exploração inadequada de séculos atrás, com a execução de práticas exercidas sem preocupações com o meio ambiente, deste modo o Estado passou a ser considerado como uma região com alto índice de impactos ambientais e sociais, contrapondo sua posição de destaque no cenário brasileiro (ENRÍQUEZ, 2009).

O Quadro1 demonstra os principais aspectos e impactos positivos e negativos que o setor incorre ao meio ambiente e à sociedade, de forma geral.

Quadro 1: Principais aspectos e impactos negativos e positivos causados pela mineração.

\begin{tabular}{|c|c|c|c|}
\hline ASPECTOS & IMPACTOS & ASPECTOS & IMPACTOS \\
\hline Remoção de solos superficiais & Assoreamento dos corpos d'água & Empregos gerados & Melhor renda e benefícios \\
\hline $\begin{array}{l}\text { Exploração Inadequada e/ou } \\
\text { demasiada }\end{array}$ & Estímulo de processos erosivos & Melhoria do PIB & Estímulo ao setor de serviços \\
\hline $\begin{array}{c}\text { Exploração próximas a locais } \\
\text { urbanos }\end{array}$ & Desvalorização dos imóveis & Aumento da demanda mundial & $\begin{array}{c}\text { Aquecimento do mercado } \\
\text { brasileiro e maior equilíbrio oferta e } \\
\text { demanda }\end{array}$ \\
\hline Rebaixamento das calhas dos rios & $\begin{array}{l}\text { Rupturas de pontes e redução das } \\
\text { matas ciliares }\end{array}$ & Inovação tecnológica & Crecimento industrial \\
\hline Ruídos provenientes de explosões & Poluição sonora & Reaproveitamento dos resíduos & Diminuição da poluição ao solo \\
\hline $\begin{array}{l}\text { Desmatamento das áreas e } \\
\text { exploração }\end{array}$ & Degradação da fauna e flora & $\begin{array}{c}\text { Fornecimento de insumos ao setor } \\
\text { da construção civil }\end{array}$ & $\begin{array}{l}\text { Aquecimento do mercado / } \\
\text { atender as necessidades da } \\
\text { sociedade }\end{array}$ \\
\hline Perfuração das rochas & Poluição do ar & Aumento das exportações & Aumento das reservas internas \\
\hline Extração incorreta de ferro & Poluição das água por lama & $\begin{array}{l}\text { Desenvolvimento da cadeia } \\
\text { produtiva }\end{array}$ & Competitividade social \\
\hline
\end{tabular}

Fonte: SILVA, 2007.

Todos os impactos negativos expostos são prejudiciais ao meio ambiente, sejam eles choques diretos ou indiretos à sociedade, fauna e flora. As intervenções legais na diminuição desses impactos por meio de políticas públicas são consideradas como embasamento para ambientalistas no controle dos impactos causados pelo setor. Outro fator são as imposições dos exportadores, que cada vez 
mais prezam pela prática da atividade menos ofensiva ao ambiente, dada a consciência decorrente da escassez já observada em algumas regiões, bem como da visualização dos efeitos negativos que o setor representa para a biota (CORRÊA, 2015).

Todavia, quando se contextualiza o setor de mineração, não é viável destacar apenas os impactos negativos provocados, já que este ramo é considerado um condicionante para a economia do Brasil. Somente o Estado de Minas Gerais é responsável pela extração de 180 milhões de toneladas/ano de minério de ferro e dispõe da maior reserva de manganês do país. Sendo assim, o número de empregos diretos gerados é expressivo, participando ativamente no aumento do PIB e proporcionando uma melhor distribuição de renda na região abordada (CORRÊA, 2015).

\section{CONCLUSÕES}

A atividade mineradora consiste na extração direta do recurso natural, portanto o contato com esses elementos propicia alterações nas propriedades físicas e químicas do ambiente, ocasionando danos drásticos no local próximo à realização da atividade. Prejuízos no campo ambiental são plenamente visíveis e de considerável gravidade, podendo influenciar não somente os locais próximos ao extrativismo, mas também a comunidade do entorno, atingindo o solo, rios e comprometendo a qualidade do ar. Foi possível identificar também impactos de caráter qualitativo como a morte da fauna e outros animais com risco de extinção, contaminação química decorrente da utilização do mercúrio, entre outros.

Além dos prejuízos encontrados no âmbito ambiental, pode-se observar impactos negativos que atingem a esfera social, já que a presença de mineradoras provoca alterações significativas à população vizinha, como por exemplo, depressões no solo, perda de valor dos imóveis, poluição sonora e alterações da qualidade do ar, gerando problemas de conservação do espaço geográfico e ocasionando o deslocamento populacional para outras áreas.

Embora, existam diversos empecilhos originários da atividade, ressalta-se sua importância econômica e social no Estado de Minas Gerais, com a geração de emprego e renda. A exploração histórica e a presença de grandes jazidas na região 


\section{Periódica Eletrânica

confere experiência e destaque comercial ao Estado, sendo interessante a manutenção da atividade econômica atrelada à implementação de estratégias ambientais mensuráveis. Assim, sugere-se a participação Estatal como agente fiscalizador, bem como a presença do poder legislativo na criação de leis e normas aplicáveis na esfera nacional para a gestão ambiental em Minas Gerais, além da divulgação da educação ambiental como mediadora de processos de conscientização, a fim de se atingir o progresso sócioeconômico junto à conservação do meio ambiente.

\section{REFERÊNCIAS}

ENRÍQUEZ, Maria Amélia Rodrigues da Silva. Mineração e desenvolvimento sustentável - é possível conciliar?. Revista Iberoamericana de Economia Ecológica. Brasília, v. 12, p. 51-66, 2009.

SILVA, João Paulo Souza. Impactos ambientais causados por mineração. Revista Espaço da Sophia.ed 1, n. 08, nov. 2007.

CORRÊA, TeltonElber. A mineração e seus efeitos socioeconômicos. Disponível em: <http://www.ibram.org.br/sites/1300/1382/00000603.pdf>. Acesso em: 01 maio 2015.

AMARAL, Antônio José Rodrigues; LIMA FILHO, Clóvis Ático. Mineração. Disponível em: <http://www.dnpm-pe.gov.br/Geologia/Mineracao.php>. Acesso em: 23 maio 2015.

BRASIL. Ministério de Minas e Energia. Setor mineral representa 4\% do PIB brasileiro. Disponível em: <http://www.brasil.gov.br/infraestrutura/2014/12/setor-mineral-representa-4-por-cento-do-pibbrasileiro>. Acesso em: 23 maio 2015.

FARIAS, Carlos Eugênio Gomes. Mineração e o meio ambiente no Brasil. Disponível em:<http://www.em.ufop.br/ceamb/petamb/cariboost_files/miner_c3_a7_c3_a3o_20e_20meio_20ambi ente.pdf>. Acesso em: 23 maio 2015.

IBRAM, Instituto Brasileiro de Mineração. Informações sobre a economia mineral no estado de Minas Gerais. Disponível em: < http://www.ibram.org.br/sites/1300/1382/00005483.pdf>. Acesso em: 23 maio 2015.

PENNA, Carlos Gabaglia. Efeitos da mineração no meio ambiente. Disponível em: < http://www.oeco.org.br/carlos-gabaglia-penna/20837-efeitos-da-mineracao-no-meio-ambiente>. Acesso em: 23 maio 2015. 